\section{Overuse of animal antibiotics threatens human health}

Richard Woodman London

Giving antibiotics to farm animals results in the emergence of resistant bacteria with potentially calamitous consequences for human health, warns a report from the United Kingdom Advisory Committee on the Microbiological Safety of Food.

The committee, which was set up to provide the government with independent expert advice, says that it is clear that some of the resistant strains seen in food animals are capable of infecting humans. Moreover, the ability of micro-organisms to transfer resistance "adds to the concerns about multiple resistant strains like [Salmonella typhimurium] entering the food chain."

The report recommends reduced reliance on the use of antimicrobials in food animal production and urges regulatory authorities to consider the resistance problem before authoris- ing veterinary medicines.

Members of the committee backed the recent European Union ban on using as growth promoters certain antibiotics that are closely related to those used in human medicine. The report stated: "Having considered the matter very carefully, we concluded it would be prudent to phase out the use as growth promoters of spiramycin, tylosin phosphate and virginiamycin which might give rise to resistance to clinical antibiotics. We felt, additionally, that those remaining for use as growth promoters-avilamycin, bambermycin, bacitracin zinc, monensin sodium and salinomycin-should be more closely controlled, with regular reviews of possible implications in human medicine."

Although the report says that there is conclusive evidence that giving antibiotics to animals

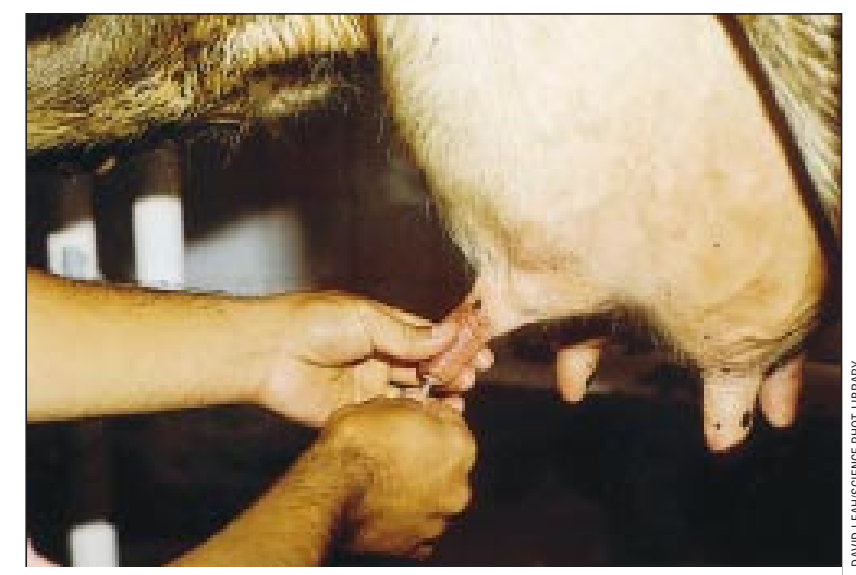

Animal food producers should reduce their reliance on antibiotics

results in the emergence of some resistant bacteria that infect humans, it points out that the extent to which this contributes to the overall problem of bacterial antibiotic resistance in humans is uncertain. It notes: "For more than a year we have tried, unsuccessfully, to discover the amounts of antibiotics used in animals in the United Kingdom, the species of animals in which they were given, and the purpose of administration. We recognise that much of this information is commercially sensitive or difficult to assemble. We nevertheless believe that a robust system to gather this information should be put in place as soon as possible."

Microbial Antibiotic Resistance in Relation to Food Safety is available from the Stationery Office, price $£ 27.50$.

\section{German doctors are unhappy about drugs budget}

Annette Tuffs Heidelberg

Patients in Germany may have to wait for prescriptions that are not strictly necessary if the overall health insurance budget of DM39bn (£13bn; \$20.8bn) for drugs and physiotherapy is exceeded before the end of the year.

This threat was issued by the Kassenärztliche Bundesvereinigung (KBV), which represents the 110000 doctors who treat patients insured with the various insurance companies. By putting patients on a waiting list for drugs, the association wants to avoid the harsh consequences of the strict budget that has been set. If doctors prescribe more than the budget allows their annual income will be cut.

The threat was condemned by the federal health ministry as well as the insurance companies, which accused the doctors of making their patients hostages. Last week, however, the doctors seemed to have reached a compromise with the Green party health minister, Andrea Fischer, and the representatives of the health insurance companies. They signed an action programme that should keep the costs for drugs and physiotherapy within the budget.

Under the programme doctors will prescribe cheaper, generic drugs. At present about $39 \%$ of all prescriptions are for generic drugs. If patients want more expensive drugs they will have to pay for them. Doctors will have to avoid using expensive drugs that do not have a proved effect. If the effect of a drug is uncertain a second opinion will be required. A similar programme will be established for physiotherapy.

The new president of the Bundesärztekammer (the Federal Medical Association), Jörg-Dietrich Hoppe, said that he was disappointed that the global budget had not been increased despite the increase in costs caused by medical innovations.

\section{Guidelines ignored on resuscitation decisions}

Roger Dobson Abergavenny

Hospital consultants are still not involved in the vast majority of "do not resuscitate" (DNR) orders despite national guidelines, according to a new report.

A team of consultants and specialists registrars who reviewed the performance at one London hospital also found that the decision making process leading up to such orders was poorly documented and that there was no record of discussions with the patients concerned.

The team, which reports its findings in the Journal of the Royal College of Physicians $(1999 ; 33: 348-50)$, says that the results are disappointing and urges consultants and senior nurses to be more involved in DNR decision making.

DNR instructions, statements made in advance that a patient should not have car- diopulmonary resuscitation in the event of a cardiac arrest, are more informally based in Britain than in a number of other countries, including the United States, where it is embodied in law in some states.

Six years ago the BMA, in conjunction with the Royal College of Nursing and the Resuscitation Council, produced guidelines whose recommendations include recording all DNR decisions (and the reasons behind these decisions) in medical and nursing notes.

The guidelines also recommended that the consultant should have the ultimate responsibility and that the patient, or where necessary the next of kin, should be involved. In the report in the Journal of the Royal College of Physicians, the research team, from the Whittington Hospital, north London, looked at the results of a number of internal audits at the hospital and found that in the last major survey carried out-last year, five years after the guidelines were published-consultants were involved in only $9 \%$ of such decisions and that there was no record in any case notes of a discussion with the patient. 